\section{Metal Ravne unterzeichnet FAC}

Im Jahr 1980 wurde die allererste INTECO ESU Anlage an das Edelstahlwerk Metal Ravne geliefert, welche noch heute unter voller Auslastung ESU-Blöcke produziert. Im August 2010 wurde der Vertrag über die Lieferung einer weiteren ESU Anlage unterzeichnet.

Das neue sehr flexible Anlagenkonzept kombiniert den Gleittiegel- und Standtiegelprozess und ermöglicht die Produktion von Blöcken mit einem Gewicht von bis zu 50 t und einem Maximaldurchmesser von $1.400 \mathrm{~mm}$. Weiters umfasst die Ausstattung nach den neuesten technischen Standards eine Schutzgashaube, koaxiales Design und ein innovatives Kontrollsystem. Es ist auch möglich in diese Anlage die erst kürzlich von INTECO patentierte stromführende Kokille einzubauen.

Die exzellente Kooperation und Zusammenarbeit zwischen INTECO

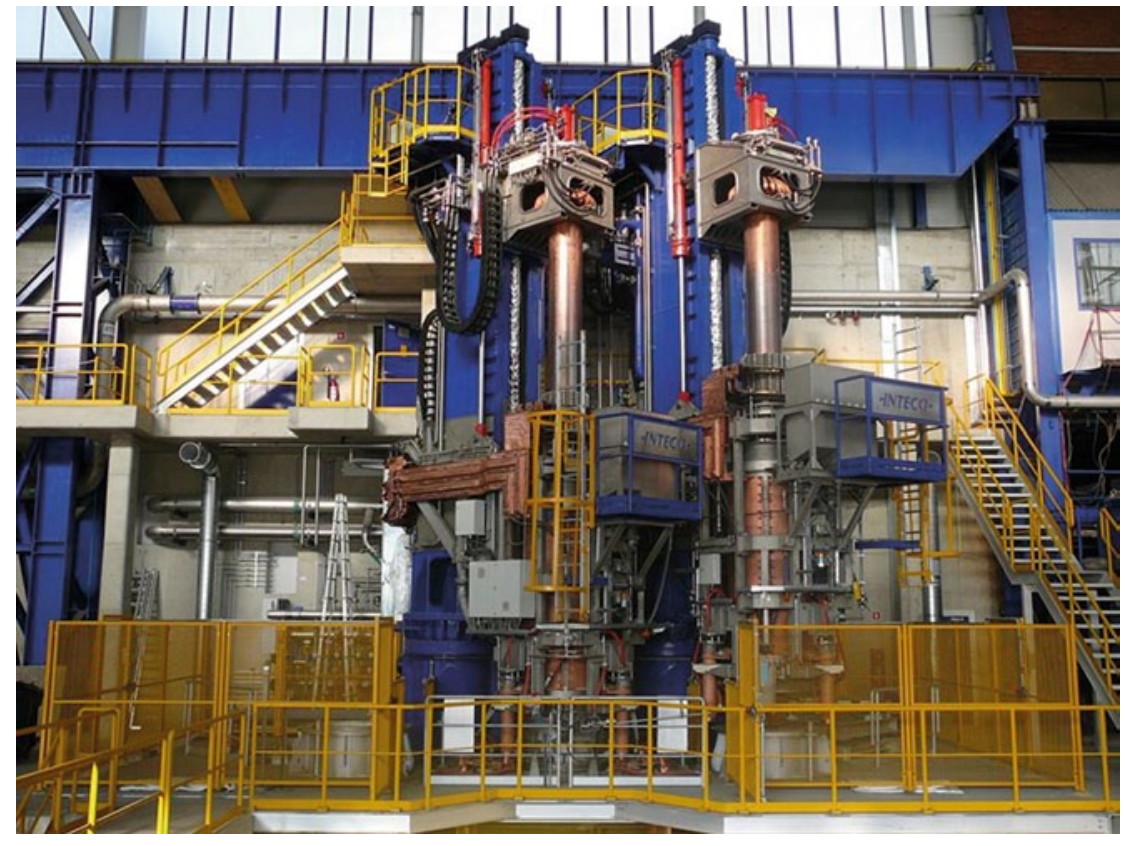

und Metal Ravne wurde durch dieses Projekt weiter gestärkt und führte im Juli 2012 zur Unterzeichnung des Final Acceptance Certificate.
Weitere Inormationen:

INTECO specialmeltingtechnologies $\mathrm{GmbH}$

Wienerstraße 25

8600 Bruck an der Mur

Österreich

URL: http://www.inteco.at/ 